\title{
Fuzzy Technique for an Inventory Model with Auto-Correlated Demand
}

\author{
P.Parvathi \\ Head \& Associate Professor \\ Department of Mathematics \\ Quaid-E-Millath Government College for Women \\ (Autonomous), \\ Chennai-600 002 \\ Tamil Nadu, India
}

\author{
J.Sujatha \\ Assistant Professor \\ Department of Mathematics \\ Quaid-E-Millath Government College for Women \\ (Autonomous), \\ Chennai-600 002 \\ Tamil Nadu, India
}

\begin{abstract}
It is commonly observed that the demand rates of many consumer goods are auto correlated and are dependent on the price and inventory amount. It is believed that the distribution of demand is independent from time to time. But in real life the demand of goods is auto-correlated. The effects of dependency and auto- correlated demand are studied under a periodic review model. An adaptive order-up-to policy based on the critical fractile is presented and a solution procedure is given. Finally we solve the model by general fuzzy technique. The results and comparative discussions are illustrated numerically.
\end{abstract}

Keywords: Fuzzy inventory model, fuzzy number, autocorrelated demand, pricing tactics, Initial net inventory level.

\section{INTRODUCTION}

A common assumption of inventory control models is that the distribution of demand is independent from one period to the next. The demand for medicines such as steroids is autocorrelated. The effect of serially-correlated demand on the determination of appropriate reorder levels for a continuousreview system was analyzed by Urban(2000).

It is usually observed in the super market that display of consumer goods in large quantities attracts more customers and generates higher demand. Thus, increased inventory levels give the customer a wider selection and increase the probability of making a sale. For example women's dress or sports clothes are depending on inventory amount displayed. Shelf-space allocation models were developed to exploit this relationship by marketing researchers and professionals like Borin et al., (1994), Corstjens and Doyle(1981), Urban (1998), Yang and Chen(1999), Zufryden(1986). Desmet and Renaudin (1998) studied on space-sales relationship and aimed that most estimates of space elasticity vary between 0.15 and 0.8 . It may seem that more inventory will result in more holding cost. But on the contrary, during the demand, which is an increasing function of the inventory level, the unnecessary holding cost will be compensated by the overall profit. Due to this relationship the inventory models has advanced into two distinct types in which the demand rate is a function of

1. The initial inventory level in the cycle.

2. The instantaneous inventory level.

The first type is consistent with the shelf-space allocation models and in the second type the demand rate changes as the inventory is decreased. Most of the researchers have focused on the deterministic problem. Due to the complexity of these models, some researchers have developed stochastic inventory-level- dependent demand patterns. Gerchak and Wang (1994) proposed a periodic-review model in which demand is represented as a deterministic function of the starting inventory level multiplied by a random variable. The effect of this dependency is that the retailer has incentive to keep higher levels of inventory despite increased holding costs as long as the item is profitable and the demand is an increasing function of the inventory level.

Thus, in turn, results in additional sales, higher fill rates and potentially greater profits T.L. Urban(2005) developed a periodic-review model in which the demand is auto-correlated as well as dependent on the level of inventory. We can expect a higher demand when the selling price is lower. If our motto is to maximize the profit then the selling price should not be neglected. A decision maker should have the opportunity to adjust the prices before the end of the sales to influence demand and to improve revenues. For example, when managers are not clear about the exact market condition facing the firm, they sometimes resort to mark-up pricing policy based on past experience that the current mark-up will generate sufficient demand.

This paper is based on R.Uthayakumar and P.Parvathi (2011) in which they developed a periodic review model with stochastic auto correlated, selling price and inventory-level dependent demand and described the characteristic of the demand during lead time and review period. A solution procedure based on the critical fractile is given. We have introduced shortage cost of storing one unit per unit time is taken as triangular fuzzy numbers, then obtained the fuzzy total cost, and defuzzified it with the signed distance method. The parameters are assumed to be triangular fuzzy numbers . Therefore, the membership function of the total profit can be calculated easily.

\section{FUZZY PRELIMINARIES}

\subsection{Definition}

Let $\mathrm{X}$ denotes a universal set. Then the fuzzy subset $\tilde{A}$ of $\mathrm{X}$ is defined by its membership function $\mu_{\tilde{A}}(x): X \rightarrow[0,1]$ which assigns a real number $\mu_{\tilde{A}}(x)$ in the interval $[0,1]$, to each element $\mathrm{x} \in \mathrm{X}$ where the value of $\mu_{\tilde{A}}(x)$ at $\mathrm{x}$ shows the grade of membership of $\mathrm{x}$

\subsection{Definition}


A fuzzy set $\tilde{A}$ on $\mathrm{R}$ is convex

if $\tilde{A}\left(\lambda x_{1}+(1-\lambda) x_{2}\right) \geq \min \left[\tilde{A}\left(x_{1}\right), \tilde{A}\left(x_{2}\right)\right]$ for all $x_{1}, x_{2} \in R$ and $\lambda \in[0,1]$.

\subsection{Definition}

A fuzzy set $\vec{A}$ in the universe of discourse $\mathrm{X}$ is called as a fuzzy number in the universe of discourse $\mathrm{X}$.

\subsection{Triangular fuzzy number}

We consider the situation where fuzzy numbers are represented by triangular membership functions. The fuzzy number $\widetilde{A}$ is said to be triangular fuzzy number if it is fully determined by $\left(a_{1}, a_{2}, a_{3}\right)$ of crisp numbers such that $\left(a_{1}<a_{2}<a_{3}\right)$ whose membership function, representing triangle, can be denoted by

$\mu_{\bar{A}}(\mathrm{X})=\left\{\begin{array}{cc}\frac{x-a_{1}}{a_{2}-a_{1}} & a_{1} \leq x \leq a_{2} \\ \frac{a_{3}-x}{a_{3}-a_{2}} & a_{2} \leq x \leq a_{3} \\ 0 & \text { otherwise }\end{array}\right.$

\subsection{The Function Principle}

The function principle was introduced by Chen [6] to treat fuzzy arithmetical operations. This principle is used for the operation for addition, subtraction, multiplication and division of fuzzy numbers.

Suppose $\tilde{A}=\left(a_{1}, a_{2}, a_{3}\right)$ and $\tilde{B}=\left(b_{1}, b_{2}, b_{3}\right) \quad$ are two triangular fuzzy numbers. Then

(i) The addition of $\tilde{A}$ and $\tilde{B}$ is

$$
\widetilde{A}+\widetilde{B}=\left(a_{1}+b_{1}, a_{2}+b_{2}, a_{3}+b_{3}\right) \quad \text { where }
$$

$a_{1}, a_{2}, a_{3}, b_{1}, b_{2}, b_{3}$ are any real numbers.

(ii) The multiplication of $\tilde{A}$ and $\tilde{B}$ is

$\widetilde{A} \times \widetilde{B}=\left(c_{1}, c_{2}, c_{3}\right)$ where

$T=\left(a_{1} b_{1}, a_{1} b_{3}, a_{3} b_{1}, a_{3} b_{3}\right)$,

$c_{1}=\min T, c_{2}=a_{2} b_{2}, c_{3}=\max T$

if $\mathrm{a}_{1}, \mathrm{a}_{2}, \mathrm{a}_{3}, \mathrm{~b}_{1}, \mathrm{~b}_{2}, \mathrm{~b}_{3}$ are all non zero positive real numbers,

then $\widetilde{A} \times \widetilde{B}=\left(a_{1} b_{1}, a_{2} b_{2}, a_{3} b_{3}\right)$.

(iii) $-\widetilde{B}=\left(-b_{3},-b_{2},-b_{1}\right)$ then the subtraction of

$\tilde{A}$ and $\tilde{B}$ is $\tilde{A}-\tilde{B}=\left(a_{1}-b_{3}, a_{1}-b_{2}, a_{3}-b_{1}\right)$

where $a_{1}, a_{2}, a_{3}, b_{1}, b_{2}, b_{3}$ are any real numbers. (iv) $\frac{1}{\widetilde{B}}=\tilde{B}^{-1}=\left(\frac{1}{b_{3}}, \frac{1}{b_{2}}, \frac{1}{b_{1}}\right)$ where $\mathrm{b}_{1}, \mathrm{~b}_{2}, \mathrm{~b}_{3}$ are all non

zero positive real numbers, then the division of $\tilde{A}$ and $\tilde{B}$ is $\frac{\tilde{A}}{\widetilde{B}}=\left(\frac{a_{1}}{b_{3}}, \frac{a_{2}}{b_{2}}, \frac{a_{3}}{b_{1}}\right)$

(v) For any real number K,

$$
\begin{aligned}
& K \tilde{A}=\left(K a_{1}, K a_{2}, K a_{3}\right) i f K>0 \\
& K \tilde{A}=\left(K a_{3}, K a_{2}, K a_{1}\right) i f K<0
\end{aligned}
$$

\subsection{Signed Distance Method}

Defuzzification of $\tilde{A}$ can be found by signed distance method. If $\tilde{A}$ is a triangular fuzzy number and is fully determined by $\left(\mathrm{a}_{1}, \mathrm{a}_{2}, \mathrm{a}_{3}\right)$, the signed distance from $A$ to 0 is defined as

$$
\begin{aligned}
& d(\tilde{A}, \tilde{0})=\int_{0}^{1} d\left(\left[A_{L}(\alpha), A_{R}(\alpha)\right], \tilde{0}\right) d \alpha \\
& =\frac{\left(a_{1}+4 a_{2}+a_{3}\right)}{4}
\end{aligned}
$$

\section{NOTATIONS AND ASSUMPTIONS 3.1 Notations}

$\mathrm{R}_{\mathrm{t}}$ : Demand in period $\mathrm{t}$.

$\mathrm{R}_{\mathrm{T}}$ : Total quantity demanded during time period $\mathrm{T}$.

L: Length of the lead time.

$\mathrm{I}_{0}$ : Inventory level at time the order is placed.

$\mathrm{I}_{1}$ : Order-up-to level. (Base stock level)

I: Initial net inventory level of an order cycle $\left(\mathrm{I}=\mathrm{I}_{1}-\mathrm{R}_{\mathrm{L}}\right)$

Q: Order quantity $\left(\mathrm{Q}=\mathrm{I}_{1}-\mathrm{I}_{0}\right)$.

$\tau$ : Length of the review period.

B: Back order fraction. (i.e., $1-\mathrm{B}$ are lost sales), $0 \leq \mathrm{B} \leq 1$

$\mathrm{h}_{1}$ : Holding cost, \$ per unit remaining at the end of the period.

S: Shortage cost, \$ per unit.

p: Acquisition cost, \$ per unit.

p': Selling price (revenue), \$ per unit. 
$\mu_{\mathrm{I}}$ : Mean of the demand distribution during the review period.

$\tilde{S}$. Fuzzy shortage cost, \$ per unit per unit time.

Inventory Level

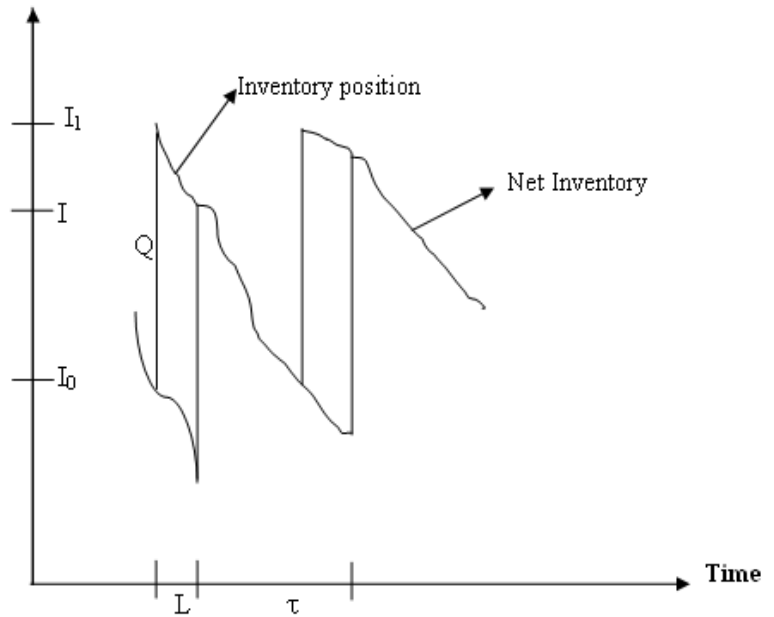

Figure. 1 Inventory Level over time

\subsection{Assumptions}

Assume that demand is auto-correlated, selling price dependent and depending on initial net inventory level. Thus the demand at any time is given by

$$
R_{t}=g_{1}(I)+\phi_{1} R_{t-1}+\varepsilon_{t}+g_{2}\left(p^{\prime}\right)
$$

where $\mathrm{g}_{1}(\mathrm{I})=\gamma+\mathrm{ye}^{\mathrm{qI}}(\mathrm{y}, \mathrm{q}<0$ and $\gamma \geq-\mathrm{y})$ is a continuous twice differentiable function of the initial net inventory level, $\varphi_{1}$ is the autocorrelation parameter, $\varepsilon_{\mathrm{t}}$ is the error term, is assumed to have the properties $\mathrm{E}\left(\varepsilon_{\mathrm{t}}\right)=0$ and constant variance $\operatorname{Var}\left(\varepsilon_{t}\right)=\sigma_{t}^{2}$.We also assume that $\sigma_{t}$ is considerably smaller than $R_{t}$, so the probability of realizing a negative demand is negligible. $\mathrm{g}_{2}\left(\mathrm{p}^{\prime}\right)$ is given by

$\mathrm{g}_{2}\left(\mathrm{p}^{\prime}\right)=\mathrm{a}-\mathrm{bp}^{\prime}$ where $\mathrm{a}>0, \mathrm{~b}>0$ (a is the scale parameter and $b$ is the shape parameter of the curve and $b$ the denotes the price sensitivity of the customers i.e., $b$ is the price elasticity).

\section{MODEL DEVELOPMENT}

The demand over the lead time and review period to determine the expected demand as follows.

$$
\sum_{i=1}^{\tau+L} E\left(R_{i}\right)=\sum_{i=1}^{\tau+L}\left[\begin{array}{l}
g_{1}(I)+\phi_{1} E\left(R_{i-1}\right)+E\left(\varepsilon_{t}\right) \\
+g_{2}\left(p^{\prime}\right)
\end{array}\right]
$$

where $E\left(R_{0}\right)$ is the most recent observed demand, $R_{0}$. The forecast $\mathrm{m}$ periods ahead (see example

Kendall and Ord, (1990)) can be expressed as $\mathrm{E}\left(\mathrm{R}_{\mathrm{m}}\right)=\mathrm{g}_{1}(\mathrm{I})+\varphi_{1} \mathrm{E}\left(\mathrm{R}_{\mathrm{m}-1}\right)+\mathrm{E}\left(\varepsilon_{\mathrm{m}}\right)+\mathrm{g}_{2}\left(\mathrm{p}^{\prime}\right)$

$$
E\left(R_{m}\right)=\left[g_{1}(I)+g_{2}\left(p^{\prime}\right)\right]\left(\frac{1-\phi_{1}^{m}}{1-\phi_{1}}\right)+\phi_{1}^{m} R_{0}, \text { since } \phi_{1} \neq 1
$$

The forecast for the period $(\tau+\mathrm{L})$ spans two order cycles, it will be a function of the initial net inventory level of the previous cycle, $I_{\text {pre }}$ as well as that of the upcoming cycle, $\mathrm{I}_{\mathrm{up}}$.

$$
\begin{aligned}
& E\left[R_{\tau+L}(I)\right]=\sum_{i=1}^{L} E\left(R_{i}\right)+\sum_{i=1}^{\tau} E\left(R_{i}\right) \\
& \left.\left.=\frac{\left[g_{1}\left(I_{u p}\right)+g_{2}\left(p^{\prime}\right)\right]}{1-\phi_{1}}\right] \tau-\phi_{1}\left(\frac{1-\phi_{1}^{\tau}}{1-\phi_{1}}\right)\right] \\
& +\frac{\left[g_{1}\left(I_{p r e}\right)+g_{2}\left(p^{\prime}\right)\right]}{1-\phi_{1}}\left[L-\frac{\phi_{1}^{\tau+L}\left(1-\phi_{1}^{L}\right)}{1-\phi_{1}}\right] \\
& +\frac{R_{0}}{1-\phi_{1}}\left[\phi_{1}\left(1-\phi_{1}^{\tau+L}\right)\right]
\end{aligned}
$$

In this model we also consider that the forecast error variance and covariance increase over time. The variance of a demand for a first order autoregressive process, m periods ahead, is

$$
\operatorname{Var}\left(R_{m}\right)=\left(\frac{1-\phi_{1}^{2 m}}{1-\phi_{1}^{2}}\right) \sigma_{\varepsilon}^{2}
$$

which approaches $\frac{\sigma_{\varepsilon}{ }^{2}}{1-\phi_{1}^{2}}$ as $\mathrm{m} \rightarrow \infty$. The covariance of demand for period $\mathrm{m}$ and period $\mathrm{n}$ (where $\mathrm{n}>\mathrm{m}$ ) is

$\operatorname{cov}\left(R_{m}, R_{n}\right)=\frac{\phi_{1}{ }^{n-m}-\phi_{1}{ }^{n+m}}{1-\phi_{1}^{2}} \sigma_{\varepsilon}^{2}$

The variance of the demand for the period $(\tau+\mathrm{L})$ is

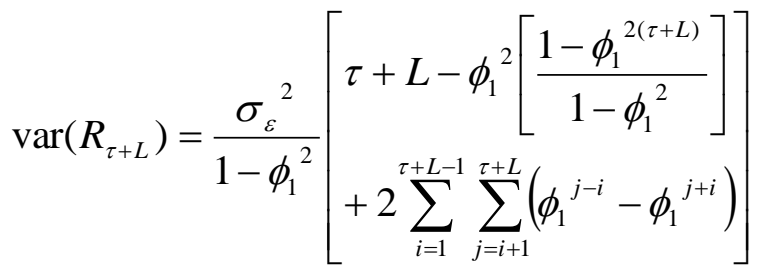

From equation (7) we see that the variance of the demand over the review period and lead-time is not a function of the initial net inventory level or the most recent demand. For most consumer goods, it seems that, the auto correlation parameter, $\varphi_{1}$, tends to be positive. Thus the variance of the demand over the lead time and the review period is greater than it would be an independent demand sequence (negative autocorrelation would have the opposite effect) resulting in a higher required safety stock. 


\subsection{Solution Methodology}

Our objective of the periodic-review model can be expressed as the following expected profit function over the review.

$Z\left(I, p^{\prime}\right)=\left(p^{\prime}-p\right)\left[\mu_{I}-(1-B) \int_{I}^{\infty}(x-I) f_{x} d x\right]$

$-h_{1} \int_{I}^{\infty}(I-x) f_{x} d x-\tilde{S} \int_{I}^{\infty}(x-I) f_{x} d x$

(8)

where $\mathrm{x}$ is the demand during the review period with density function $\mathrm{f}_{\mathrm{x}}$ and cumulative distribution function $\mathrm{F}_{\mathrm{x}}$

$$
\begin{aligned}
\mu_{I_{u p}} & =\sum_{i=1}^{\tau} E\left(R_{i}\right) \\
= & \sum_{i=1}^{\tau}\left[\begin{array}{l}
{\left[g_{1}\left(I_{u p}\right)+g_{2}\left(p^{\prime}\right)\right]\left(\frac{1-\phi_{1}{ }^{i}}{1-\phi_{1}}\right)} \\
+\phi_{1}{ }^{i} E\left(R_{\tau+L-\tau}\right)
\end{array}\right]
\end{aligned}
$$

Let $\xi_{\tau}=\frac{\phi_{1}\left(1-\phi_{1}{ }^{\tau}\right)}{1-\phi_{1}}$ then

$\mu_{I_{u p}}=\frac{\tau-\xi_{\tau}}{1-\phi_{1}}\left[g_{1}\left(I_{u p}\right)+g_{2}\left(p^{\prime}\right)\right]$

$+\left(\frac{1-\phi_{1}^{L}}{1-\phi_{1}}\right) \xi_{\tau}\left[g_{1}\left(I_{p r e}\right)+g_{2}\left(p^{\prime}\right)\right]+\phi_{1}^{L} \xi_{\tau} R_{0}$

$\pi\left(I_{\text {up }}, \mathrm{p}^{\prime}\right)$ is concave with respect to $\mathrm{I}_{\text {up }}$ and $\mathrm{p}^{\prime}$. We can find the solutions by differentiating the above equation partially with respect to $\mathrm{p}^{\prime}$ and $\mathrm{I}_{\mathrm{up}}$ and equate them to zero. That is by solving the following equations simultaneously.

$$
\begin{aligned}
& \left\lfloor\left(p^{\prime}-p\right)(1-B)+\tilde{S}+h_{1}\right\rfloor \\
& +(1-B) I_{u p}\left[\begin{array}{l}
h_{1}\left(1-\phi_{1}\right) \\
-\left(p^{\prime}-p\right)\left(\tau-\xi_{\tau}\right) y q e^{q I_{u p}}
\end{array}\right]=0
\end{aligned}
$$

$$
\begin{gathered}
{\left[\left(p^{\prime}-p\right)(1-B)+\tilde{S}\right]\left(1-\phi_{1}\right)+} \\
F_{I_{u p}}=\frac{\left(p^{\prime}-p\right)\left(\tau-\xi_{\tau}\right) y q e^{q I_{u p}}}{\left(1-\phi_{1}\right)\left[\left(p^{\prime}-p\right)(1-B)+\tilde{S}+h_{1}\right]}+I_{u p} f_{I_{u p}}
\end{gathered}
$$

As both mean of the demand distribution, $\mathrm{E}\left[\mathrm{R}_{\tau+\mathrm{L}}\left(\mathrm{I}_{\mathrm{up}}\right)\right]$ and the critical fractile, $\mathrm{FI}_{\mathrm{up}}$ are functions of $\mathrm{I}_{\mathrm{up}}$, a direct calculation cannot be made. We can use the following algorithm to find the optimal values.

\subsection{Algorithm}

Demand parameters $\rightarrow \mathrm{a}, \mathrm{b}, \gamma, \mathrm{y}, \mathrm{q}, \varphi, \sigma^{2}$

Cost parameters $\rightarrow \mathrm{p}, h_{1}, \widetilde{S}$

Other parameters $\rightarrow \tau, \mathrm{L}, \mathrm{B}, \mathrm{R}_{0}, \mathrm{I}_{0}, \mathrm{I}_{\text {pre }}$

Step 0: Input all the parameters Let $\mathrm{j}=0$.

Step 1: Put $\mathrm{I}_{\text {up }}(0)=\mathrm{I}_{\text {pre }}$ in equation 11 to find $\mathrm{p}^{1}$.

Step 2: Let $\mathrm{j}=\mathrm{j}+1$

Step 3: Put $I_{u p}(\mathrm{j}), \mathrm{p}^{\prime}$ in equation 12 to find $F_{I_{u p}}$. If $\mathrm{FI}_{\mathrm{up}} \geq 1$ then set $F_{I_{u p}}=1-\Delta$ where $\Delta=0.0001$.

Step 4: Calculating order-up-to Level $\mathrm{I}_{1}(\mathrm{j})$.

Find $E\left[R_{\tau+L}\left(I_{u p}\right)\right]$ and $\operatorname{Var}\left[R_{\tau+L}\right]$ from

$$
\begin{aligned}
& E\left[R_{\tau+L}\left(I_{u p}\right)\right]=\frac{\left[\begin{array}{l}
{\left[\gamma+y e^{q I_{u p}}\right.} \\
+\left(a-b p^{\prime}\right)
\end{array}\right]}{\left(1-\phi_{1}\right)}\left[\tau-\frac{\phi_{1}\left(1-\phi_{1}^{\tau}\right)}{1-\phi_{1}}\right] \\
& +\left[\frac{\left[\gamma+y e^{q I_{p r e}}\right]+\left(a-b p^{\prime}\right)}{\left(1-\phi_{1}\right)}\right]\left[L-\frac{\phi_{1}^{\tau+1}\left(1-\phi_{1}{ }^{L}\right)}{1-\phi_{1}}\right] \\
& +\frac{R_{0}}{\left(1-\phi_{1}\right)}\left[\phi_{1}\left(1-\phi_{1}^{\tau+L}\right)\right]
\end{aligned}
$$

$$
\begin{gathered}
\operatorname{Var}\left[R_{\tau+L}\right]=\left[\frac{\sigma_{\varepsilon}{ }^{2}}{\left(1-\phi_{1}^{2}\right)}\right]\left[+2 \sum_{i=1}^{\tau+L-1} \sum_{j=i+1}^{\tau+\phi_{1}^{2}}\left[\frac{\left(1-\phi_{1}^{2(\tau+L)}\right)}{1-\phi_{1}^{2}}\right]\right. \\
\left.\phi\left[\frac{I_{1}(j)-E\left(R_{\tau+L}\left(I_{u p}\right)\right.}{\left.\sqrt{\operatorname{var}\left[R_{\tau+L}\right]}\right]}\right]=F_{I_{u p}}{ }^{j+i}\right]
\end{gathered}
$$

where $\varphi$ is the standard normal cumulative distribution function. From the normal table find corresponding ordinateZ.

$\left[\frac{I_{1}(j)-E\left(R_{\tau+L}\left(I_{u p}\right)\right.}{\sqrt{\operatorname{var}\left[R_{\tau+L}\right]}}\right]=Z$ 


$$
I_{1}(j)=Z \sqrt{\operatorname{var}\left[R_{\tau+L}\right]}+E\left(R_{\tau+L}\left(I_{u p}\right)\right.
$$

Step 5: Update the initial net inventory level.

$$
I_{\text {up }}(j)=I_{1}(j)-E\left[R_{L}\left(I_{u p}(j)\right)\right] \text { where }
$$

$$
\begin{aligned}
& E\left[R_{L}\left(I_{u p}(j)\right)\right] \\
& =\frac{\left[\gamma+y e^{q I_{u p}}+\left(a-b p^{\prime}\right)\right]}{1-\phi_{1}}\left[L-\frac{\phi_{1}\left(1-\phi_{1}{ }^{L}\right)}{1-\phi_{1}}\right] \\
& +R_{0} \phi_{1}\left[\frac{1-\phi_{1}^{\tau}}{1-\phi_{1}}\right]
\end{aligned}
$$

Step 6: If $\left|I_{\text {up }}(j)-I_{\text {up }}(j-1)\right| \geq \delta$ put $I_{\text {up }}(j)$ in equation 11 to find $\mathrm{p}$ and go to step 2. Otherwise go to step 7 .

Step 7: Find $I 1=I_{1}(j), I_{\text {up }}=I_{\text {up }}(j), Q=I_{1}-I_{0}$

Step 8: Find the profit.

\section{NUMERICAL EXAMPLE}

To illustrate the above algorithm the following numerical example is considered.

Example 1: $\mathrm{a}=12, \mathrm{~b}=0.2, \gamma=3.75, \mathrm{y}=-0.5, \mathrm{q}=-0.2, \varphi_{1}=0.7, \sigma_{\varepsilon}^{2}$ $=36, \mathrm{p}=\$ 6, h_{1}=\$ 0.5, \tilde{S}=\$(2,2.5,3), \tau=12, \mathrm{~L}=4, \mathrm{~B}=0.4, \mathrm{R}_{0}=50$, $\mathrm{I}_{0}=192, \mathrm{I}_{\mathrm{pre}}=282, \delta=0.001$. We can initialize $\mathrm{I}_{\text {up }}$ as $\mathrm{I}_{\text {pre }}$ and $\mathrm{p}^{\prime}$ as 6 . We get the optimal values of the following: Order quantity $\mathrm{Q}=301.3865$, selling price $=\$ 40.832$ and profit $=\$ 8899.04$

\begin{tabular}{|c|c|c|c|c|c|c|c|}
\hline $\mathbf{j}$ & $\mathbf{I}_{\mathrm{up}}(\mathbf{j}-\mathbf{1})$ & $\mu_{I_{u p}}$ & $F_{I_{u p}}$ & $\mathbf{I}_{\mathbf{1}}$ & $\mathbf{Q}$ & $\mathbf{E}\left[\mathbf{R}_{\mathbf{L}}\left(\mathbf{I}_{\mathbf{u p}}\right)\right]$ & $\mathbf{I}_{\mathbf{u p}}(\mathbf{j})$ \\
\hline $\mathbf{1}$ & 282 & 582.8287 & 0.8333 & 1057.5 & 775.45 & 196.6597 & 364.044 \\
\hline $\mathbf{2}$ & 364.044 & 582.8287 & 0.8333 & 1057.5 & 693.45 & 196.6597 & 359.923 \\
\hline $\mathbf{3}$ & 359.923 & 582.8287 & 0.8333 & 1057.5 & 693.4112 & 196.6597 & 360.054 \\
\hline $\mathbf{4}$ & 360.054 & 582.8287 & 0.8333 & 1057.5 & 697.4012 & 196.6597 & 360.050 \\
\hline $\mathbf{5}$ & 360.050 & 582.8287 & 0.8333 & 057.5 & 697.4052 & 196.6597 & 360.050 \\
\hline
\end{tabular}

\section{CONCLUSION}

We have framed fuzzy inventory model in which demand rate is an exponential function of the initial net inventory level, auto correlated and also price sensitive. No research has been conducted that incorporates all these effects in an inventorycontrol frame work. One can expect higher demand when the selling price is lower. We defuzzified the value of Shortage cost by signed distance method. Using this algorithm we found the optimal values of inventory level, selling price and also the corresponding profit. Our numerical example show that it can be achieved successfully.

\section{REFERENCES}

[1] Borin.N., Farris, P.W.,Freeland, J.R., 1994. A model for determining retails product category assortment and shelf space allocation. Decision Sciences 25(3), 359-384.

[2] Charnes, J.M., Marmorstein, H., Zinn, W., 1995. Safety stock determination with serially correlated demand in a periodic review inventory system. Journal of the Operational Research Society 46(8), 1006-1013.

[3] Chen, S.H., Operations of fuzzy numbers with function 
principle, Tamkang Journal of Management Sciences, 6(1), (1985), pp 13-26.

[4] Chen, J.M., Chen, L.T., 2004. Pricing and Lot sizing for a deteriorating item in a periodic review inventory system with shortages, Journal of the Operational Research Society 55, 892-901.

[5] Corstjens, M., Doyle, P., 1981. A model for optimizing retail space allocations Management Science 27(7), 822833.

[6] Desmet, P.,Renaudin, V.,1998.Estimation of product category sales responsiveness to allocated shelf space. International Journal of Research in Marketing 15(5), 443-457.

[7] Gerchak, Y., Wang, Y., 1994. Periodic-review inventory models with inventory-level dependent demand . Naval Research Logistics 41(1), 99-116.

[8] Kendall, M.G., Ord, J.K., 1990. Time Series, $3^{\text {rd }}$ edition . Oxford University Press, New York.

[9] L.A. Zadeh, "Fuzzy Sets", Inform \& Control, No.8, PP 338-353, 1965

[10] Lau, H.S., Wang, M.C., 1987. Estimating the lead time demand distribution when the daily demand is nonnormal and autocorrelated. European Journal of Operational Research 29(1), 60-69.

[11] Nahmias, S., 1997. Production and Operation Analysis, $3^{\text {rd }}$ Edition. Irwin, Chicago.

[12] Ray, W.D., 1980. The significance of correlated Demands and variable lead times for stock control policies. Journal of the Operational Research Society 31(2), 187-190.

[13] Ray, W.D., 1981. Computation of reorder levels when the demands are correlated and the lead time random. Journal of the Operational Research Society32(1), 27-34.

[14] Urban, T.L. 1998. An inventory-theoretic approach to product assortment and shelf-space allocation. Journal of Retailing 74(1), 15-35.

[15] Urban, T.L., 2000. Reorder level determination with serially-correlated demand. Journal of Operational Research Society 51(6), 762-768.

[16] Urban T.L., 2005. A periodic-review model with seriallycorrelated, inventory-level dependent demand, International Journal of Production Economics 95, 287295.

[17] Uthayakumar, R., Parvathi, P., 2011. Inventory model with pricing tactics for demand in auto correlated products. International Journal of Advanced Manufacturing Technology 52, 833840.

[18] Wolfe. H.B., 1968. A model for control of style merchandise. Industrial Management Review 9(2), 69. 82.

[19] Yang, M.H., Chen, W.C., 1999. A study on shelf space allocation and management. International Journal of Production Economics 60-61, 309-317

[20] Yang, P.C., 2004. Pricing strategy for deteriorating items using quantity discount when demand is price sensitive, European Journal of Operational Research, 157, 389-397.

[21] You, P.S., 2005. Inventory Policy for Products with Price and time-dependent demands, Journal of the Operational Research Society, 56, 870-873.

[22] Zufryden, F.S., 1986. A dynamic programming approach for product selection and supermarket shelf-space allocation Journal of the Operational Research Society, 37(4), 413-422. 